\title{
Multiscale investigations in a mesoscale catchment - hydrological modelling in the Gera catchment
}

\author{
P. Krause, F. Bäse, U. Bende-Michl, M. Fink, W. Flügel, and B. Pfennig \\ Department for Geoinformatics, Hydrology and Modelling, Friedrich-Schiller-University, Jena, Germany \\ Received: 23 January 2006 - Revised: 22 May 2006 - Accepted: 3 July 2006 - Published: 26 September 2006
}

\begin{abstract}
The application of the hydrological processoriented model $\mathrm{J} 2000(\mathrm{~J} 2 \mathrm{~K})$ is part of a cooperation project between the Thuringian Environmental Agency (Thüringer Landesanstalt für Umwelt und Geologie - TLUG) and the Department of Geoinformatics of the Friedrich-SchillerUniversity Jena focussing on the implementation of the EU water framework directive (WFD). In the first project phase J2K was parametrised and calibrated for a mesoscale catchment to quantify if it can be used as hydrological part of a multi-objective tool-box needed for the implementation of the WFD. The main objectives for that pilot study were:
\end{abstract}

1. The development and application of a suitable distribution concept which provide the spatial data basis for various tasks and which reflects the specific physiogeographical variability and heterogeneity of river basins adequately. This distribution concept should consider the following constraints: The absolute number of spatial entities, which forms the basis for any distributive modelling should be as small as possible, but the spatial distributed factors, which controls quantitative and qualitative hydrological processes should not be generalised to much. The distribution concept of hydrological response units HRUs (Flügel, 1995) was selected and enhanced by a topological routing scheme (Staudenrausch, 2001) for the simulation of lateral flow processes.

2. J2K should be calibrated for one subbasin of the pilot watershed only. Then the parameter set should be used on the other subbasins (referred as transfer basins) to investigate and quantify the transferability of a calibrated model and potential spatial dependencies of its parameter set. In addition, potential structural problems in the process description should be identified by the transfer

Correspondence to: $\mathrm{P}$. Krause

(p.krause@uni-jena.de) to basins which show a different process dominance as the one which was used for calibration does.

3. Model calibration and selection of efficiency criteria for the quantification of the model quality should be based on a comprehensive sensitivity and uncertainty analysis (Bäse, 2005) and multi-response validations with independent data sets (Krause and Flügel, 2005) carried out in advance in the headwater part of the calibration basin.

4. To obtain good results in the transfer basins the calibrated parameter set could be adjusted slightly. This step was considered as necessary because of specific constraints which were not of significant importance in the calibration basin. This readjustment should be carried out on parameters which show a sensitive reaction on the identified differences in the environmental setup.

5. Potential scaling problems of the process description, distribution concept or model structure should be identified by the comparison of the modelling results obtained in a small headwater region of the calibration basin with observed streamflow to find out if the selected efficiency measures show a significant change.

\section{Introduction}

The European Water Framework Directive (WFD), adopted in 2000 , requires a general ecological protection and a minimum chemical standard to be achieved in all European surface waters based on the watershed scale. All member states of the EU have to develop river basin management action plans to achieve these goals up to 2015. In Germany this procedure has to be coordinated and decided by the federal water agencies in cooperation with their respective ministries. In the state of Thuringia the Thuringian Environmental Agency (TLUG) is in charge of the work tasks for the implementation the WFD. To quantify the applicability of hydrological

Published by Copernicus GmbH on behalf of the European Geosciences Union. 


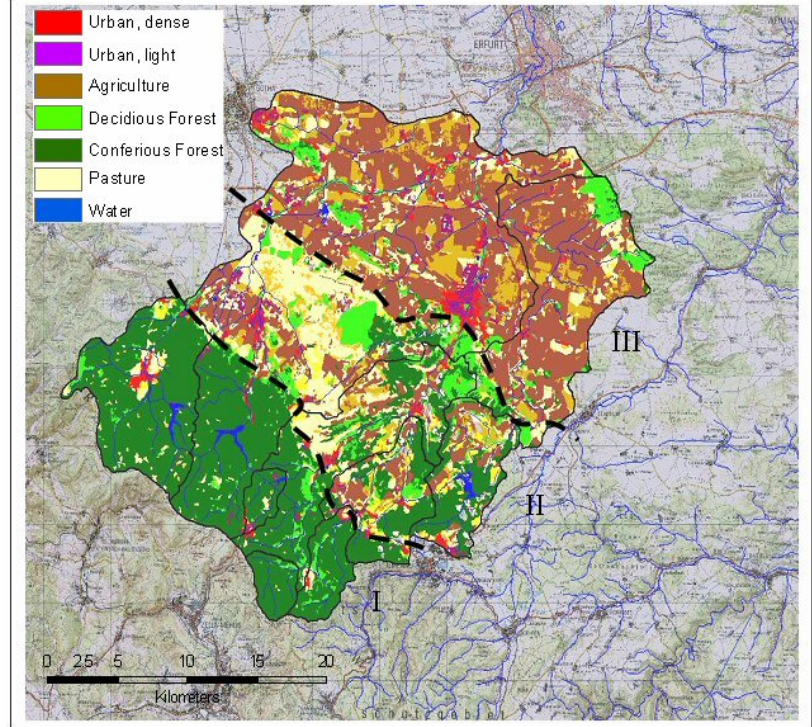

Fig. 1. Land-use/land-cover in the Gera basin. The roman numbers indicate the different typical regions discussed in the following paragraphs

and solute transport process models for the derivation of scenarios and management alternatives a cooperation project between the TLUG and the Departure of Geoinformatics at the Friedrich-Schiller-University in Jena was started. The long term outcome of this cooperation will be the development of an integrated tool-box which provides custom-tailored software solutions for the challenges exposed by the WFD.

The first stage of the project did comprise the parametrisation and application of a distributed hydrological modelling system in a selected pilot watershed to define an appropriate basis for ongoing development in terms of distributed hydrological quantitative process descriptions. For this the object and process-oriented hydrological model J2000 (e.g. Krause 2001, 2002) was selected. The results of this work stage are described in this paper.

\section{Catchment description}

For the study presented in this paper the catchment of the Gera river in Thuringia was selected. The selection was based on specific criteria determined by the overall project objectives:

1. The catchment should be representative for central Germany in terms of its natural conditions: It should comprise different topographical conditions like midmountain regions, low-land areas and intermediate regions with rolling terrain. The most important landuse/land-cover forms such as larger forest, mixtures of pasture and agriculture, intensive agriculture and urban areas should be located inside the basin and it should comprise the typical soil types and hydro-geological formations. In addition, the catchment should show various climatological and hydrological regimes ranging from cold and wet regions, which features high precipitation rates, low evapotranspiration and a considerable snow influence, down to warm and dry regions with low precipitation and higher evapotranspiration.

2. The catchment should be of upper meso to lower macro scale size to analyse different scales ranging from small headwater catchments (area $<50 \mathrm{~km}^{2}$ ) up to upper meso-scale basins ( $a r e a \approx 800-1500 \mathrm{~km}^{2}$ ).

3. The basin's water and land-use management should cover the typical problem set which allows to investigate most of the regional problems in terms of the EUWFD: i.e. water quality of the different rivers in the catchment should cover the full range from good ecological status to major pollution by diffuse sources as well as point sources like waste water inflows. Quantitative water management should comprise water storage in reservoirs for flood prevention, power generation and drinking water supply as well as groundwater subtraction for drinking water supply or irrigation purposes.

Based on these criteria, the catchment of the river Gera was selected for this project. The catchment has an area of $850 \mathrm{~km}^{2}$ and is situated south of the city Erfurt. The elevation ranges between $983 \mathrm{~m}$ in the South-West and $200 \mathrm{~m}$ a.s.l. at the basin outlet in the North. The main flow direction is from SW to NE. Figure 1 shows the land-use/land-cover of the catchment and its segmentation into three major regions (marked with roman numbers I-III).

Region I, the Thuringian Forest (Thüringer Wald), features higher elevation (600-983 ma.s.l) and a typical midmountain relief, where deep incised valleys with narrow valley floors and steep slopes $\left(25-45^{\circ}\right)$ can be found. The geology of this region is mostly crystalline schist with only minor groundwater capacity in clefts. Soils are predominantly cambisols and in some parts leptosols and podsols with low to moderate useable field capacity of ca. $90 \mathrm{~mm}$. Land-cover is dominated by managed coniferous forest and smaller pasture areas used for stock farming. The mean annual precipitation (MAP) amounts to $1300 \mathrm{~mm} / \mathrm{a}$ and is relativly high for that German region. The estimated mean annual evapotranspiration (MAE) is approximately $400 \mathrm{~mm} / \mathrm{a}$. These values result in a mean annual runoff generation (MAR) of ca. $900 \mathrm{~mm} / \mathrm{a}$, which equals a runoff-precipitation-ratio of 0.69 . The low mean annual temperature (MAT) of only $5-6^{\circ} \mathrm{C}$ results in a considerable snow cover in winter and snow melt driven high runoff in spring (TLUG 2004). Because of the high runoff generation and the thread of floods originating from this region, a number of water reservoirs has been constructed in the last 80 years, which can be seen in Fig. 1 marked as water in the legend. 
Region II, the Ilm-Saale limestone plateau (Saale-Ilm Muschelkalkplatte), follows in N-E direction. This area is classified by lower elevation (300-600 m a.s.l) and, in comparison to region I, a smoother relief. Slopes barely exceeds $10^{\circ}$; however there are a few locations featuring steeper slopes with values up to $30^{\circ}$. Triassic limestones dominate this region, which is characterised by karst phenomena. Soils are predominantly cambisols, and in some parts rankers with low to moderate usable field capacity of $80 \mathrm{~mm}$. Land-use is a mixture of forested areas, pastures and meadows used partly for stock farming as well as agricultural areas. The MAR is with $800 \mathrm{~mm} / \mathrm{a}$ ca. $40 \%$ lower than in region I, whereas the MAT is higher $\left(7-8^{\circ} \mathrm{C}\right)$, which results also in a higher MAE of ca. $460 \mathrm{~mm} / \mathrm{a}$. Because of the lower rainfalls and the higher evapotranspiration, the runoff generation is $65 \%$ lower than in region I. The MAR is estimated to be $340 \mathrm{~mm} / \mathrm{a}$, which results in a runoff-precipitation-ratio of 0.34. Near the eastern border of the catchment the flood retention reservoir Heyda is located.

Region III, the central Thuringian farmland (Innerthüringer Ackerhügelland), is situated in the N-E of the basin. This region is classified by low elevation between only 200-300 m a.s.l. and a mostly very flat terrain with slopes predominantly lower than $3^{\circ}$. The geology is formed of sand and silt stones from the Keuper featuring a reasonable loess cover in some areas. The low relief gradient combined with the geological situation results in thick and very fertile chernozems and luvisols, which have very high usable field capacity of $220 \mathrm{~mm}$. Because of the good soils, almost the entire region is used for intensive agriculture. The low elevations leads to a reduction of the MAP which is only $635 \mathrm{~mm} / \mathrm{a}$ in this region and a slight increase in the MAT of $1{ }^{\circ} \mathrm{C}$. The temperature increase results in a MAE of $540 \mathrm{~mm} / \mathrm{a}$. Both, the decrease in rainfall and the increase in temperature, result in the reduction of runoff generation, which is only $90 \mathrm{~mm} / \mathrm{a}$ in the long term mean and, therefore, to a low runoff-precipitation-ratio of only 0.15 .

\section{Model description and setup}

One of the goals of the project's first phase was a hydrological assessment and modelling of the hydrological conditions to provide a basis for the coupling of nutrient transport modules. Since the main objective of the project is the development of a tool-set to assist the scientific sound derivation of management plans for the EU-WFD, the representation of the internal process dynamics and a good reproduction of the runoff generation and lateral runoff transport processes was the main priority.

\subsection{The J2000 modelling system}

The J2K modelling system (Krause, 2001, 2002) was used for the simulation of the hydrological dynamics of the Gera catchment. J2K is a modular process oriented hydrological system, which implements single hydrological processes as encapsulated process modules. Beside the process modules for the simulation of the runoff generation and runoff concentration dynamics $\mathrm{J} 2 \mathrm{~K}$ offers routines for the regionalisation and correction of climate data, the calculation of additional input data e.g. solar radiation, potential evapotranspiration according to Penman-Monteith or absolute humidity, which are often not available as measured values. In addition, tools for sensitivity and uncertainty analysis as well as plotting capabilities to produce diagrams of the model results are available.

The temporal resolution of $\mathrm{J} 2 \mathrm{~K}$ is in either daily or hourly time steps. Spatial resolution or catchment distribution is carried out by hydrological response units (HRUs) which are connected by a lateral routing scheme to simulate lateral water transport processes. This allows a fully distributed hydrological modelling of river basins. The delineation of the response units is described in more detail in Sect. 3.2.

The process implementation for the simulation of the runoff generation is realised in a conceptual way using different storages for the single components. The interception module uses a simple storage approach according to Dickinson (1984), which calculates a maximum interception storage capacity based on the leaf area index of the respective land-use. As long as this maximum capacity is not exceeded, precipitation is stored in the actual interception storage, which is depleted by evaporation. When the maximum storage capacity is exceeded any surplus of rainfall is treated as throughfall and passed to the next module.

The snow module combines empirical or conceptual approaches with more physically based routines. Mostly, it follows the approach of Knauf (1976), which was enhanced in some parts. The module calculates different state variables of the snow cover such as snow depth, snow density and snow water equivalent, which can be used for process oriented multi response validation.

The most complex part of $\mathrm{J} 2 \mathrm{~K}$ is the soil water balance module, which reflects the central role of the soil zone as a regulation and distribution system, and interacts with nearly all other $\mathrm{J} 2 \mathrm{~K}$ process modules. The soil zone of each response unit is subdivided into two storages according to the specific pore volumes of the soil. The middle pore storage (MPS) represents the pores with a diameter of $0.2-50 \mu \mathrm{m}$ in which water is held against gravity but can be subtracted by an active tension e.g. plant transpiration. Whereas the large pore storage (LPS) represents the large and macro pores $(>50 \mu \mathrm{m})$, which cannot hold water against gravity. Therefore, LPS is considered as the source of all subsurface flow processes in J2K. Infiltration is estimated by an empirical approach that takes the actual soil moisture into account. Water, which is not able to infiltrate, is up to a certain amount stored at the surface as depression storage, any surplus is treated as surface runoff and routed to the next unit. Infiltration water is distributed to MPS and LPS determined by the actual 


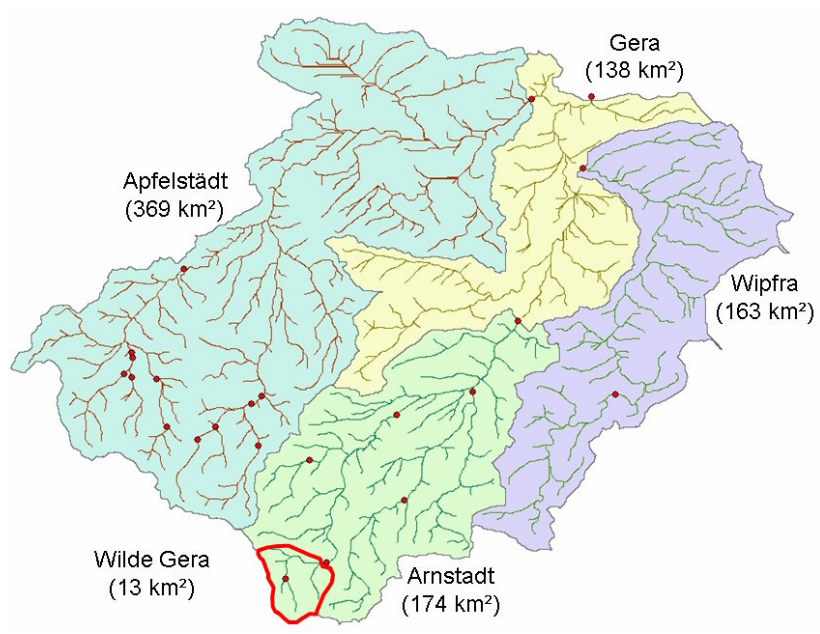

Fig. 2. The subbasins of the Gera used for the nested catchment modelling approach.

water saturation of MPS. Water stored in MPS is reduced by the plant transpiration determined by the potential ETP and the actual water saturation of MPS. Water in the LPS is distributed into a lateral component (interflow) and a vertical component (percolation) depending on slope. The percolation is passed to the groundwater module whereas interflow is routed to the next unit or a connected river reach. When water is left in LPS at the end of the time step, it can be partly used to replenish the MPS.

The groundwater module follows a simple storage concept, which implements two groundwater storages for each response unit. The first storage RG1 can be considered as the withered layer on top of the bedrock, which shows a quick hydrological reaction and short residential times. The second storage RG2 represents the saturated groundwater aquifer with longer residential times and a more damped hydrological reaction. Input as percolation is distributed between the two storages depending on the slope of the response unit.

Runoff concentration and flood routing in the channel network, which is simulated as a network of river reaches is considered explicitly by $\mathrm{J} 2 \mathrm{~K}$. Lateral flows originating from the runoff generation calculated for each response unit are passed to adjacent units until the receiving unit is connected to a river reach. In this case, the runoff produced by this unit is transferred to the reach segment. Flood routing in the channel network is calculated by a simplified kinematic wave approach, which uses Manning's formula to calculate flow velocity.

For the calibration of the model all modules contain a number of calibration parameters that have to be adapted based on the comparison with measured stream flow. Overall, 28 parameters can be calibrated. It has to be noted that all calibration parameters are effective parameters, which have the same value for the entire basin. To limit the degree of

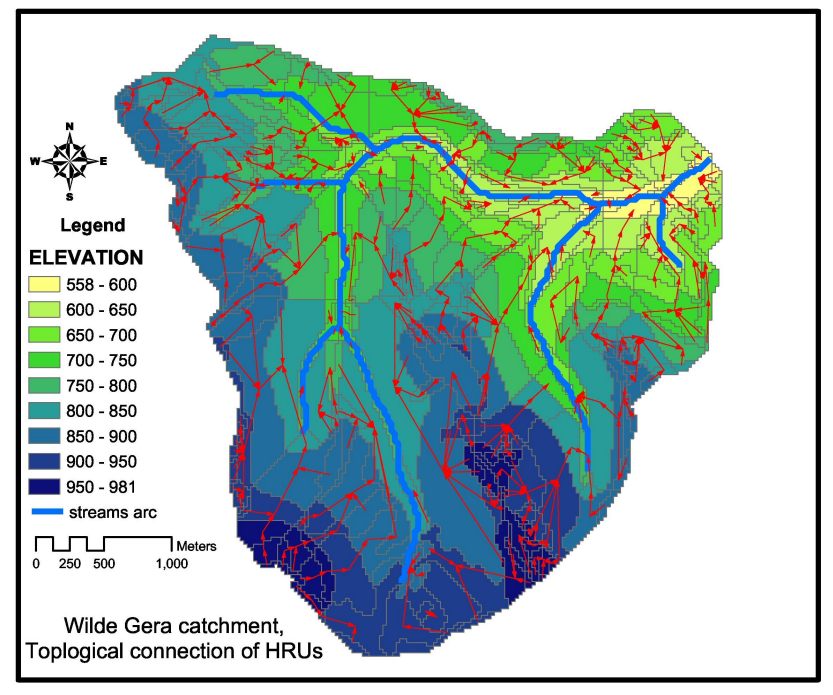

Fig. 3. HRU polygons in the Wilde Gera subbasin with the topological connections marked as red arrows.

freedom, calibration for single response units is not possible. For validation purposes, each module state variable can be read out either as a mean value for the whole catchment or as distributed values in space and time. Different temporal aggregation steps (e.g. daily, monthly, yearly or long term) can be selected for the distributed output.

\subsection{Catchment distribution}

For the hydrological modelling of the runoff dynamics of the Gera basin the catchment was divided into four subbasins shown in Fig. 2, which are different in size and in terms of environmental, climatological and hydrological conditions. In the upper part of subbasin Arnstadt the small headwater catchment Wilde Gera is located, which is a well investigated and modelled test catchment (e.g. Michl 1999, Krause and Flügel 2005).

Physiographical hydrological response units (HRUs) were delineated in a GIS for each subbasin. The delineation was based on classified topographical parameters (elevation, slope, aspect), land-use classes (derived from LANDSAT), soil-types and hydro-geological units (Flügel, 1995; Bongartz, 2002; Staudenrausch, 2001). For the delineation, the single GIS layers are partly reclassified and combined by overlay analysis. The resulting polygons are further generalised based on their attribute set and neighbourhood to reduce the overall numbers of spatial model entities.

The delineation of HRUs for the entire Gera catchment resulted in 13769 entities featuring areas between 0.02 to $2.5 \mathrm{~km}^{2}$. A topological routing scheme was derived in the GIS for the simulation of lateral runoff generation processes, which determines the HRU polygon connections. Figure 3 shows the HRU polygons of the Wilde Gera catchment to- 
gether with topological connections as red arrows draped on the underlying elevation.

From Fig. 3 the process oriented character of the HRU distribution concept becomes obvious. The more hydrological dynamic regions of the catchment (e.g. steep slopes near river reaches) show a high spatial resolution with many small polygons whereas regions with lower dynamics (e.g. higher plateaus in the south) are resolved by a fewer number of larger polygons. This allows an efficient simulation of the catchment's hydrological dynamics with a minimum amount of redundancy.

\subsection{Model parametrisation}

The parameters of $\mathrm{J} 2 \mathrm{~K}$ describing a catchment and its hydrological response can be divided into two groups: (1) The spatially distributed but temporal static descriptors (= spatial attributes), which describe the spatial heterogeneity and variability and (2) the spatial and temporal static calibration parameters used for the adaptation of the model's response. To limit the degrees of freedom during model calibration, only the second group should be changed to obtain a good modelling result, whereas the first group is quantified inside the GIS based on the input data layers.

The spatial attributes of the Gera catchment (coordinates, elevation, slope, aspect, soil type, landuse type, hydrogeological type) for each HRU were derived and stored in J2K-compliant parameter files. In a second parameter file physical soil parameters (aircapacity, field capacity) are defined according to the horizon description of the soil map for each soil type. In a third parameter file, physical vegetation parameters (LAI, albedo, stomata resistance, effective height, effective rooting depth) were stored for eleven landuse classes. Effective parameters describing the groundwater domain (storage capacity and recession coefficients for different aquifers) are contained in a fourth parameter file. The interaction between the parameter files were solved by relation between the soil, landuse and hydrogeological descriptors in the HRU parameter file and respective descriptors in the other files. During model initialisation the information is read out of the files and transferred as spatial attributes to the HRU objects of the model.

Climatological time series used as drivers for the model application were available in daily time steps from three synoptical climate stations and 14 precipitation gauges from 1979 to 2000. The climate stations provided measurements of minimum, mean and maximum temperature, wind speed, sunshine hours and relative humidity. This driving data had been checked for data gaps, homogeneity and plausibility and finally transferred to J2K-compliant data files. Observed runoff values for model validation were available for 15 runoff gauges (shown in Fig. 1 as red dots).

\subsection{Model application}

Five models were set up for the simulation, one for each of the subcatchments. Only the time series of the hydrological years 1990 to 2000 was used to avoid data quality problems and possible inhomogeneities related to the reunification of Germany. The entire time series was split up into a calibration period (1990-1993) and a validation period (19942000). In scope of the project the following calibration strategy was defined:

1. Calibration of the most sensitive parameters for the subbasin Arnstadt in order to obtain a reasonable fit between observed and predicted runoff (Nash-Sutcliffe efficiency E2 $\approx 0.7$, logarithmic Nash-Sutcliffe efficiency $\log \mathrm{E} 2 \approx 0.6$ and a relative volume error rel.VE $\approx \pm 10 \%$ (Krause et al., 2005)).

2. Quantification of model quality during validation period.

3. Transfer of the whole parameter set to the subbasins Wipfra, Apfelstädt and lower Gera together with an identification of the calibration parameters most likely to change due to the change of the hydrological system's dynamics of the respective subbasins.

4. Recalibration of only those parameters and quantification of model quality during validation period.

5. Comparison of modelling results in the Wilde Gera subbasin obtained from the parameter set of step 1 with observed runoff values and modelling results from a detailed calibration of the Wilde Gera (Krause and Flügel, 2005).

The identification of the most sensitive parameters was based on a detailed sensitivity and uncertainty analysis carried out for the Wilde Gera basin (Bäse, 2005). This work demonstrated that 10 of the 28 calibration parameters showed a very sensitive reaction to the Nash-Sutcliffe efficiency and 8 partly different parameters to the log-Nash-Sutcliffe efficiency. Only 4 of the parameters were sensitive to the volume error. The threshold for the criteria for a reasonable good fit for step 1 was defined subjectively but care was taken that all three criteria were considered. Hereby, variable hydrological behaviour (peak flow, mean and low flow, water balance) could be quantified together.

Model quality was quantified by the data from the validation period, which was not used during model calibration. By this split-sample-test (Klemes, 1986) evidence is given that the model's parameter set is representing the hydrological process dynamics correct not only during the calibration period but also using independent driving data.

The transfer of the calibrated parameter set should prove that the model's parameters are valid also for other environmental conditions and spatial scales. Since not all of the features that influence the hydrological dynamics of the three 


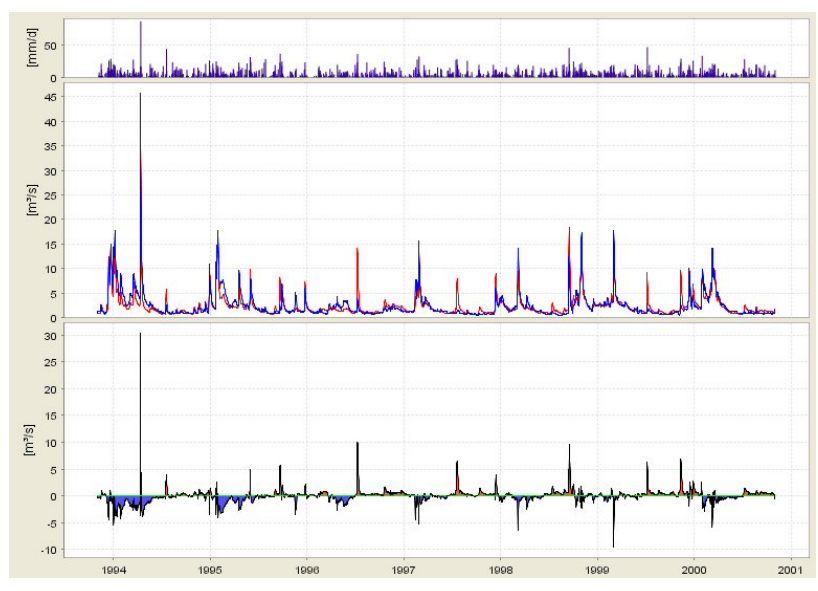

Fig. 4. Simulated (red line) and observed (blue line) runoff in the subbasin Arnstadt in the validation period. The upper panel shows the precipitation input as catchment mean, the lower panel the absolute difference between observation and prediction.

transfer subbasins are existent in the Arnstadt catchment, a recalibration of selected parameters was necessary. The first parameter included in this selection is responsible for capillary rise (capRise from 0.01 to 1.0 ) from groundwater into the unsaturated soil zone which is most likely to occur in broad riparian areas that can not be found in the Arnstadt basin. Particularly, low flows during the summer period can be reduced by this parameter. The second parameter (LPSout from 4.0 to 5.0) is the drainage factor for LPS and is therefore responsible for the outflow of mobile water from the soil zone. The adaptation was necessary to account for the lower topographical dynamics of the transfer basins, which is not fully covered by the process equations. For the same reason the third parameter, which controls the flow velocity in the stream channel (TA from 1.0 to 1.5 ), had to be readjusted to reflect the lower stream flow dynamics in the transfer basins. In general, the adaptation of LPSout and TA resulted in a less dynamic hydrograph behaviour.

\section{Results}

The calibration of $\mathrm{J} 2 \mathrm{~K}$ in the subbasin Arnstadt was undertaken for the period of 1989 to 1993 until the visual inspection of the hydrograph showed a sufficient reproduction of the hydrological dynamics and the three efficiency criteria were close to the values described above. The values achieved for the criteria during calibration are shown in the upper part of Table 1. The value of E2 was a little bit lower than the targeted threshold of 0.7 and the volume error was a little bit higher. This was accepted for three reasons: (1) The model needs about one year to initialise its storages which results in a systematic underprediction during that time, (2) the calibration period was known as a relative dry period com- pared to the validation period and (3) the main goal of the calibration was to achieve a relative good value for all three criteria together.

In the next step the calibrated parameter set was used to simulate the validation period without any changes. The simulated and observed runoff is shown in Fig. 4, the efficiency criteria in the lower part of Table 1. During the validation period much better values for all three efficiency criteria could be achieved. The visual comparison of the predictions between calibration and validation period shows that $\mathrm{J} 2 \mathrm{~K}$ performs better in the latter one. Beside the good representation of the overall dynamics the plot of Fig. 4 shows some interesting discrepancies between measured and simulated streamflow. In the middle of the hydrological years 19961999 single overpredicted peak flows occur, which are related to high precipitation input in summer.

In summary the reproduction of the hydrological dynamics by the calibrated parameter set was considered good enough to be transferred to the other subbasins.

The calibrated parameter set was then used to model the hydrological dynamics of the other subbasins Apfelstädt, Wipfra and Lower Gera. The models were recalibrated slightly as described in Sect. 3.4 to reflect special conditions which are not existent or not of dominant influence in the Arnstadt basin. The resulting efficiency values are shown in Table 1 for the three basins. It is obvious from the table that nearly all values in the transfer basins are lower than those of Arnstadt. In particular the subbasin Wipfra shows not satisfactorily efficiencies and high volume error values. Nevertheless the hydrological dynamics were captured to a certain degree as the plots of the validation period (Fig. 5) show.

The visual inspection of the simulated and observed hydrograph of the subbasin Wipfra helps in explaining these values. (1) The overall runoff variability is lower compared to the other basins, which leads in general to lower efficiency measures (Krause et al., 2005). (2) The prediction shows six distinct and sharp peaks which are not existent in the observed records. The reason for the missing peaks in the observation is the reservoir Heyda, located in the upper part of the basin, which was constructed in the 80th of last century for flood retention. The runoff despite the peaks was quite well reproduced by $\mathrm{J} 2 \mathrm{~K}$.

The hydrograph (Fig. 5) of subbasin Apfelstädt which covers all three different regions described in Sect. 2 shows a systematic overprediction during nearly the whole validation period most obvious during low flow conditions and a similar overprediction of peak flows as in the subbasin Wipfra.

The lower Gera subbasin was modelled with the parameter set calibrated for Apfelstädt and Wipfra without any further adaptation. Then the observed runoff at the catchment outlet was compared with the superimposed simulated runoff of the subbasins Apfelstädt, Wipfra, Arnstadt and lower Gera. The efficiency values for the total catchment are shown in column 4 of Table 1 . Here better values could be achieved than in the two subbasins discussed above but slightly worse values than 
Table 1. Efficiency measures for calibration and validation period in the different subbasins $(E 2=$ Nash-Sutcliffe, logE2 $=$ Nash-Sutcliffe with logartithmic values, $\mathrm{RVE}=$ relative volume error; ${ }^{1}$ Arnstadt parameter set, ${ }^{2}$ specific calibration).

\begin{tabular}{ccccccc}
\hline & Arnstadt & Apfelstädt & Wipfra & Gera & $\begin{array}{c}\text { Wilde } \\
\text { Gera }\end{array}$ & $\begin{array}{c}\text { Wilde } \\
\text { Gera }^{2}\end{array}$ \\
\hline \multicolumn{7}{c}{ Calibration period } \\
\hline E2 & 0.68 & 0.50 & -1.04 & 0.67 & 0.69 & 0.82 \\
logE2 & 0.62 & 0.47 & -0.37 & 0.73 & 0.65 & 0.82 \\
RVE & $-12.7 \%$ & $18.6 \%$ & $40.5 \%$ & $10.8 \%$ & $-21.0 \%$ & $0.43 \%$ \\
\hline \multicolumn{7}{c}{ Validation period } \\
\hline E2 & 0.81 & 0.61 & 0.56 & 0.74 & 0.81 & 0.82 \\
logE2 & 0.78 & 0.29 & -0.03 & 0.75 & 0.76 & 0.72 \\
RVE & $4.0 \%$ & $29.0 \%$ & $-3.8 \%$ & $9.9 \%$ & $2.1 \%$ & $6.95 \%$ \\
\hline
\end{tabular}

those calculated for subbasin Arnstadt. The reason for this can be seen in the facts that the efficiency at the outlet shows some kind of mean value of the values from the respective subbasins. In addition, some of the errors are averaged out by the nesting of the simulations, e.g. the negative volume error of Arnstadt is compensated by the positive volume errors of Wipfra/Apfelstädt and vice versa.

Finally the runoff from the subbasin Wilde Gera was extracted from the Arnstadt simulation and compared with the observed runoff at gauge Gehlberg, without any modelling or recalibration. The idea was (1) to find out if the upper part which is very homogeneous in terms of land-use, soils, and geology show significant other efficiency values than at the gauge of the whole subbasin and (2) compare the results with a specifically calibrated J2K model of the Wilde Gera (Krause and Flügel 2005). The efficiency criteria for the calibration and validation were very similar to those of the Arnstadt basin, which shows that $\mathrm{J} 2 \mathrm{~K}$ is able to reproduce the hydrological dynamics inside the catchment with a comparable quality as for the whole modelled subbasin. The efficiency values of the specific calibrated model were better than those achieved with the Arnstadt calibration (see Table 1).

\section{Discussion and Conclusions}

The distributed process-oriented hydrological model $\mathrm{J} 2 \mathrm{~K}$ was applied to a mesoscale catchment in Germany. The whole catchment was split into four subbasins, which were modelled separately. For each subbasin hydrological response units were delineated to provide a process oriented representation of the catchment's variability in terms of natural environmental conditions. The single HRU polygons were connected by a topological routing scheme which allows the simulation of lateral processes important for the modelling of runoff concentration. The largest advantage of the HRU approach is the process oriented view on a catchment's spatial characteristics which drives the hydrological

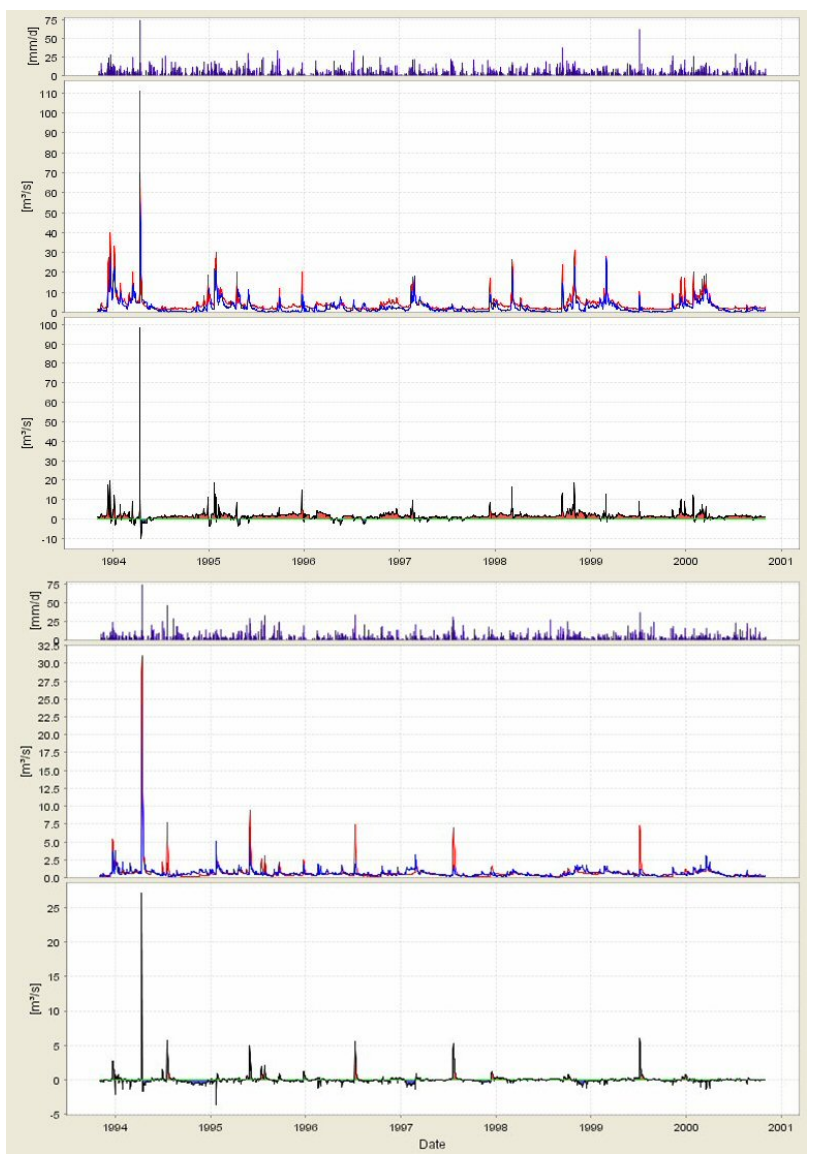

Fig. 5. Simulated (red line) and observed (blue line) runoff in the subbasins Apfelstädt (upper part) and Wipfra (lower part) in the validation period together with precipitation and differences.

behaviour. With this distribution concept high resoluted spatial information can be obtained and used in heterogeneous regions and less resoluted information in more homogeneous areas which results in a process driven minimal number of 
spatial entities and smaller models. With a raster based approach the same spatial information density would result in a much larger number of cells. For the Gera model described here a spatial resolution of $25 \times 25 \mathrm{~m}$ was used for the delineation of the 13715 HRUs, the same information density in a raster model would have resulted in ca. 1350000 grid cells. The largest disadvantage of the HRU approach are the scientifically more challenging work steps which needs profound GIS and process knowledge to obtain a good distribution of the catchment. In addition, the determination of the topological interconnections between the single spatial entities and the river reaches is a time consuming task.

The calibration and application of $\mathrm{J} 2 \mathrm{~K}$ for the subbasin Arnstadt showed that the model was able to reproduce the hydrological dynamics with a sufficient degree of quality. The validation using the split sample test (Klemes, 1986) proved that the model was able to represent the process interaction and hydrological dynamics also for an independent time series. An interesting fact was that during the validation period better efficiencies could be acquired than in the calibration period. This fact can be explained by multiple reasons: (1) During the first year of the calibration period the model need to initialise itself to obtain reasonable values for all state variables and is therefore constraint by the uncertain starting conditions. As the validation period follows directly after the calibration period the model's starting conditions are defined better by the four year model run in advance, which results in better simulation values in particular in the first year of the period. (2) The validation period features higher rainfalls than the calibration period and higher runoffs as a follow up. In addition, significantly higher overall variability, which can be expressed by the standard statistical descriptors of the runoff values: mean $=1.6 \mathrm{~m}^{3} / \mathrm{s}, \mathrm{s}=1.6$, relV $=97 \%$ in the calibration period and mean $=2.4 \mathrm{~m}^{3} / \mathrm{s}, \mathrm{s}=2.6$, relV $=110 \%$ could be found for the validation period. As shown in Krause et al. (2005) such higher variabilities of the observations can produce higher Nash-Sutcliffe efficiency values, because the variance of the observation forms the denominator of the equation.

The application of the calibrated parameter set to the remaining subbasins with only slight adjustments showed that the transfer of a calibrated model to other catchments produces results of similar quality. Even though the efficiencies went down in the transfer basins the visual inspections of the simulated hydrographs showed a good representation of the hydrological dynamics. The responsible deviations of the simulation from the observation can be explained at least partly by specific natural and management conditions which have influence on the subbasin's runoff. Here first of all the influence of a couple of reservoirs used for flood retention, power production and drinking water supply in the headwater regions of the basins has to be mentioned. Because $\mathrm{J} 2 \mathrm{~K}$ does not consider such reservoirs it overpredicts the runoff at certain times. This is most obvious for a couple of runoff peaks in the summer months (Figs. 4 and 5), but probably might also have influence during low flow periods. As a second source for errors karst features in the middle part of the Gera basin can be considered. For this region stream flow losses are known and mapped but not quantified in terms of volume yet. Nevertheless it can be expected that they have influence on the streamflow in particular during low flow periods. An indication that these reasons are responsible for the simulation errors is the good match of comparable flood peaks in the winter periods. Here, because of the higher water availability, the need to hold back water in the reservoirs for power production or drinking water supply is not as urgent as it is in summer and the influence of the streamflow losses in relation to the overall runoff is lower in winter than it is in summer.

Another potential source of error can be seen in the daily time steps of the model. This temporal resolution does not allow the precise consideration of rainfall events with high intensities and short durations, because the model knows only about the entire precipitation volume per day. Therefore runoff peaks resulting from infiltration excess (Hortonian runoff) can not be simulated precisely.

The karst features, the influence of reservoirs as well as the problems with high intensive rainfalls have the most significant impact during summer. As such features are not considered adequately by the current version of $\mathrm{J} 2 \mathrm{~K}$ deviations of the simulation from the observation should occur. In addition, the simulation plots (Fig. 4 and 5) show some systematic underprediction in the winter and spring months. The underprediction in winter and spring can be directly related to snow melt events. A closer inspection of the difference plots shows that it is more a problem of timing than of volume. This implies the indication, that the modelling of the temporal behaviour of the snow course and in particular the snow melt is responsible for such model errors.

The comparison of the efficiencies obtained with the same parameter set for the much smaller Wilde Gera subbasin showed nearly the same values than those of the whole basin. This is an indication that the process description and distribution concept of $\mathrm{J} 2 \mathrm{~K}$ is valid for a range of scales. A specifically calibrated model for this small headwater catchment did produce slightly better results for E2 both during calibration and validation. The more low flow sensitive efficiency criteria $\log \mathrm{E} 2$ was better during calibration but higher in the validation period (Krause and Flügel 2005). Again this is an indication that deviations of the model simulation from the observed time series is more related to the process description and rather a problem of scale.

The results of the study presented here can be concluded as follows: The hydrological modelling system J2K was able to reproduce the hydrological dynamics of the Gera basin and its subcatchments with a sufficient quality. Specific deviations of the simulation results from the observation could be explained and will lead the further development of $\mathrm{J} 2 \mathrm{~K}$ in the future. The nested calibration approach used for this study showed that it is possible to calibrate J2K for a smaller 
subbasin and to obtain good simulation results in other subbasins by the transfer of the entire parameter set combined with a slight adjustment of selected model parameters. This approach has some specific advantages over an parametrisation and calibration at the catchment outlet only: (1) The runoff at the outlet of larger basins provides an integrative signal which represents the average hydrological dynamics. Hereby specific processes taking place only in some regions of the basin can no longer be identified, because they have no dominant influence on the total runoff. The implication in terms of model calibration are that the values of single parameters which control such processes cannot be identified precisely by the comparison between simulation and observation because they do not show a sensitive reaction. (2) The application of the same model in different subbasins can help in the identification of structural model problems and in tracing the responsible process implementations. In addition dependencies of single parameter values or process implementations from scale or specific conditions in term of environmental configuration as well as human management can be identified better.

In general, it is more likely that parameter sets obtained with the nested catchment approach for larger basins are resulting in a better spatial representation of the runoff generation and concentration processes than a calibration on the catchment outlet only.

Acknowledgements. The authors thank the Thüringer Landesanstalt für Umwelt und Geologie for funding, Cornelia Barth (DRI, Reno, Nevada) for manuscript revision, R. Rödel and J. Wolf for their kind reviews, and the conveners of the workshop for the excellent organisation.

Edited by: R. Barthel, J. Götzinger, G. Hartmann, J. Jagelke, V. Rojanschi, and J. Wolf

Reviewed by: anonymous referees

\section{References}

Arnold, J. R. and Fohrer, N.: SWAT2000: current capabilities and research opportunities in applied watershed modelling, Hydrol. Processes, 19, 563-572, 2005.

Bäse, F.: Beurteilung der Parametersensitvität und der Vorhersagesicherheit am Beispiel des hydrologischen Modells J2000; Master-Thesis at the Department of Geoinformatics, FriedrichSchiller-University Jena, http://www.geogr.uni-jena.de, 2005.

Bongartz, K.: Untersuchung unterschiedlicher Flächendiskretisierungs- und Modellierungskonzepte für die hydrologische Modellierung am Beispiel Thüringer Vorfluter, Dissertation, FriedrichSchiller Universität Jena, 2002.

Dickinson, R. E.: Modelling evapotranspiration for threedimensional global climate models; in: Climate Processes and Climate Sensitivity, edited by: Hansen, J. E. and Takahashi, T., Geophys. Monograph. Ser., 29, Washington, 1984.

Flügel, W.-A.: Delineating Hydrological Response Units by Geographical Information System Analyses for Regional Hydrological Modelling using PRMS/MMS in the Drainage Basin of the River Bröl, Germany, Hydrol. Processes, 9(3/4), 423-436, 1995.

Klemes, V.: Operational testing of hydrological simulation models, Hydrol. Sci. J., 31, 1, 13-24, 1986/

Knauf, D.: Die Abflubildung in schneebedeckten Einzugsgebieten des Mittelgebirges, Technischer Bericht Nr. 17, Institut für Hydraulik und Hydrologie, TH Darmstadt, 1976.

Krause, P.: Das hydrologische Modellsystem J2000 - Beschreibung und Anwendung in groen Flugebieten, Schriften des Forschungszentrums Jülich, Reihe Umwelt/Environment, Band 29, 2001.

Krause, P.: Quantifying the impact of land use changes on the water balance of large catchments using the J2000 model, Phys. Chem. Earth, 27, 663-667, 2002.

Krause, P., Boyle, D., and Bäse, F.: Comparison of different efficiency criteria for hydrological model assessment, Adv. Geosci., 5, 89-97, 2005, http://www.adv-geosci.net/5/89/2005/.

Krause, P. and Flügel, W.-A.: Integrated research on the hydrological process dynamics from the Wilde Gera catchment in Germany, Headwater Control VI: Hydrology, Ecology and Water Resources in Headwaters, IAHS Conference, Bergen 2005.

Michl, Ch.: Prozessorientierte Modellierung des Wasserhaushaltes zweier Quelleinzugsgebiete im Thüringer Wald, Dissertation, Friedrich-Schiller Universität, Jena, 1999.

Staudenrausch, H.: Untersuchungen zur hydrologischen Topologie von Landschaftsobjekten für die distributive Flussgebietsmodellierung, Digitale Bibliothek Thüringen, http://www. db-thueringen.de, 2001. 